\title{
ALOHTONA FLORA NASELJA JEZERA NA OTOKU MURTERU (DALMACIJA, HRVATSKA)
}

\author{
ALIEN FLORA OF THE SETTLEMENT OF JEZERA ON THE \\ ISLAND MURTER (DALMATIA, CROATIA)
}

\section{Marija Pandža}

\section{SAŽETAK}

$\mathrm{U}$ radu je prikazana analiza alohtone flore naselja Jezera na otoku Murteru koja broji 248 vrsta i podvrsta.

Brojem vrsta najzastupljenije su porodice Asteraceae s.s. (30 svojti; $12,10 \%$ ), a od rodova se ističu rodovi Prunus (7 svojti) i Citrus (6 svojti). Među životnim oblicima najzastupljeniji su fanerofiti (109 svojti; 43,95\%) i terofiti (64 svojte; 25,81\%).

Od 248 svojti njih $128(51,61 \%)$ dolazi isključivo u kulturi. Ostalih 120 svojti $(48,39 \%)$ imaju sposobnost preživljavanja izvan uzgoja: 86 svojti su neudomaćene, povremeno preživljavaju izvan uzgoja (casual), 14 je udomaćenih (naturaliziranih), a 20 je invazivnih.

Prema geografskom podrijetlu najveći broj vrsta i podvrsta potječe iz Amerike (80 svojti; 32,26\%), a zatim slijede svojte iz Azije (69 svojti; 27,83\%).

Od 248 vrsta i podvrsta iz ovoga rada njih 95 su nove za floru otoka Murtera. Ukupna flora otoka Murtera sada broji 977 vrsta i podvrsta.

Ključne riječi: alohtona flora, naselje Jezera, otok Murter, Dalmacija, Hrvatska

\section{ABSTRACT}

This paper presents the analysis of alien flora of the settlement of Jezera on the island Murter, which comprises 248 species and subspecies.

The most common plant family, according to the number of species, is the family Asteraceae s.s. (30 taxa; $12.10 \%$ ). Genera that are especially common include genus Prunus (7 taxa) and Citrus (6 taxa). Among plant life-forms, the most common are phanerophytes (109 taxa; 43.95\%) and therophytes $(25.81 \%)$. 
Marija Pandža: Alohtona flora naselja Jezera na otoku Murteru (Dalmacija, Hrvatska)

Out of 248 taxa $128(51.61 \%)$ are found only in cultivation. Remaining 120 taxa $(48.39 \%)$ have low ability to survive outside cultivation: 86 taxa are undomesticated, occasionally surviving outside cultivation (casual), 14 of them are domesticated (naturalized), and 20 taxa are invasive plants.

According to geographical origin, most species and subspecies originate from American continent (80 taxa; 32.26\%), after which the plants originating from Asia are most common (27.83\%).

Among 248 species and subspecies described in this paper, 95 are new for the flora of the Murter island. The total flora of the Murter island now comprises 977 species and subspecies.

Key words: alien flora, Jezera settlement, the Murter island, Dalmatia, Croatia

\section{UVOD}

Teritorijalno i administrativno otok Murter nalazi se na sjeverozapadnom dijelu šibenskog arhipelaga i Šibensko-kninske županije te ima status najvećeg naseljenog otoka u županiji. Površina mu je $17,58 \mathrm{~km}^{2}$ (Duplančić Leder i dr., 2004.), a pravac pružanja dinarski (sjeverozapad-jugoistok) (sl. 1).

$\mathrm{Na}$ otoku su četiri naselja Murter, Betina, Tisno i Jezera. Naselje Jezera smješteno je u prirodno zaštićenoj uvali na jugoistoku otoka (sl. 1) i administrativno pripada općini Tisno, a pruža se u unutrašnjost do uvale Lovišća u kojoj je turističko naselje. U Jezerima je 2011. godine živjelo 886 stanovnika. U zadnjih 20-tak godina najvažnija djelatnost stanovnika je turizam te ribarstvo i poljodjelstvo (maslinarstvo).

Prvi podatci o flori otoka Murtera potječu iz 19 st. (Visiani, 1842.-1852.). Nakon 150 godina od prvih florističkih podataka Visianija započinje temeljito istraživanje flore i vegetacije otoka (Pandža, 1998., 2003., 2004.; Pandža, i dr., 2004., 2005.; Milović i Pandža, 2010.).

Veći broj autora navodi pojedinačne nalaze ili manji broj vrsta za otok Murter (Pavletić i Pandža, 1994.; Milović i Randić, 2001.; Pandža i dr. 2001.; Pandža, 2002.; Milović, 2004.).

Prema literaturnim podatcima za floru otoka Murtera zabilježene su 882 svojte od koji je 201 u kulturi (Milović i Pandža, 2010.). 
Otok Murter se nalazi $\mathrm{u}$ području $\mathrm{C}_{\mathrm{sa}}$ klime po Köpennu koju karakteriziraju vruća ljeta $\mathrm{s}$ temperaturom srpnja $\geq 22{ }^{\circ} \mathrm{C}$ (Šegota i Filipčić, 2003.). Otoku Murteru najbliža klimatološka postaju u Šibeniku za razdoblje 1976.-1996. imala je srednju godišnju temperaturu $15,4{ }^{\circ} \mathrm{C}$ (Državni hidrometeorološki zavod). U bioklimatskom smislu otok pripada bioklimi sveze Quercion ilicis. Vegetacija te sveze u fitogeografskom pogledu pripada eumediteranskoj vegetacijskoj zoni mediteranske fitogeografske regije (usp. Trinajstić, 1998.).

Ciljevi istraživanja bili su popisati sve alohtone svojte u autokampu Lovišća i naselju Jezera, obaviti taksonomsku i ekološku analizu. Svojtama odrediti geografsko podrijetlo i stupanj udomaćenosti.

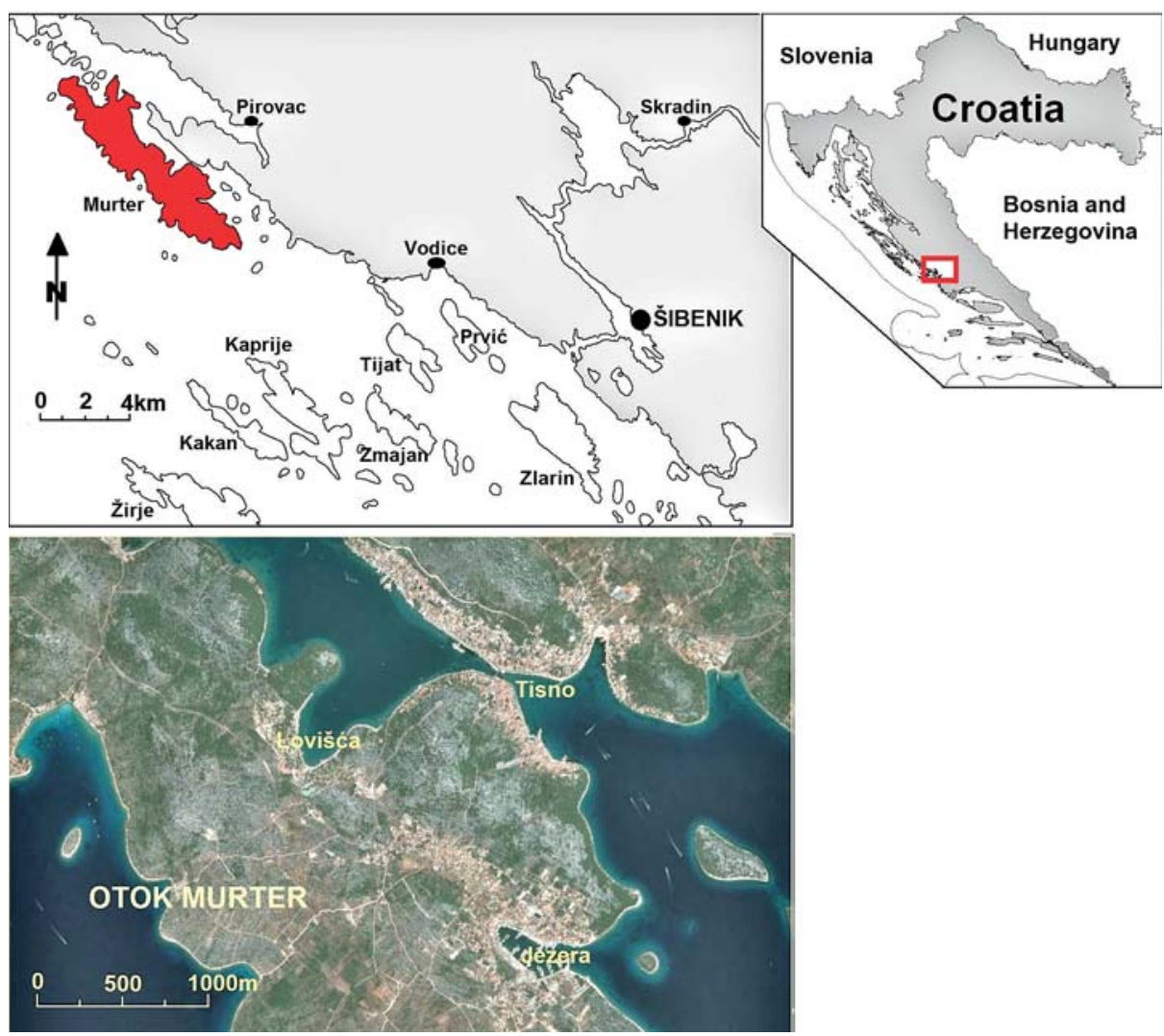

Slika 1. Područje istraživanja.

Figure 1 The area investigated. 
Marija Pandža: Alohtona flora naselja Jezera na otoku Murteru (Dalmacija, Hrvatska)

\section{METODE}

Terenskim istraživanjem strane (alohtone) flore Jezera obuhvaćeno je turističko naselje Lovišća i naselje Jezera s marinom. Istraživanja su obavljena tijekom 2014. i 2016. godine. U popis su uključene sve alohtone svojte, tj. one koje ni na jednom dijelu Hrvatske ne dolaze samoniklo.

Determinacija svojta obavljena je pomoću standardne literature: Tutin i dr. (1964.-1980., 1993.), Pignatti (1982.), Walters i dr. (1984.-1989.), Domac (1994.), Cullen i dr. (1995.-1999.).

Nomenklatura svojta u popisu flore usklađena je prema bazi podataka Flora Croatica (Nikolić, 2017.), a za one svojte koje nisu zastupljene u navedenom izvoru prema djelu Europaean Garden Flora (Walters i dr., 1984.-1989.; Cullen i dr., 1995.-1999.) što je označeno zvjezdicom (*) ispred imena svojte.

Za svaku svojtu u popisu flore navedeni su sljedeći podatci: životni oblik, znanstveno ime, stupanj udomaćenosti i geografsko podrijetlo. U florističkoj listi vrste su navedene abecednim redom u okviru rodova, porodica i viših sistematskih kategorija.

Razdioba svojta prema životnom obliku obavljena je prema Horvatu (1949.), a uobičajene kratice se navode ispred imena svojte: T (therophyta), G (geophyta), H (hemicryptophyta), Ch (chamaephyta), P (phanerophyta) i Hy (hydrophyta).

Alohtone svojte Jezera su svrstane u četiri kategorije s obzirom na stupanj naturalizacije, a u skladu s preporukama Richardson i dr. (2000.), Pyšek i dr. (2004.), Boršić i dr. (2008.) i Mitić i dr. (2008.):

- $\quad$ isključivo u kulturi (kult)

- imaju sposobnost privremenog preživljavanja izvan uzgoja (povremene cas)

- $\quad$ samostalno se razmnožavaju izvan uzgoja bez utjecaja čovjeka (udomaćene, naturalizirane neinvazivne vrste - nat)

- $\quad$ naturalizirane invazivne vrste (inv).

Procjena stupnja udomaćenosti i razvrstavanje svojta u navedene kategorije obavljeni su prema utvrđenom stanju na istraživanom području.

Podatci o geografskom podrijetlu svojta korišteni su iz više izvora: Pignatti (1982.), Tutin i dr. (1968.-1980., 1993.), Cullen i dr. (1995.-1999.), Walters i dr. (1984.-1989.). 
Nove svojte za floru otoka Murtera označene su znakom $(\bullet)$ složenim iza geografskog podrijetla u popisu flore. U popisu flore za invazivne vrste koje su ranije zabilježene u zagradi su navedeni ime autora i godina objavljivanja rada.

\section{REZULTATI}

FLORISTIČKA LISTA

\section{Cupressaceae}

$\mathrm{P} *$ Cupressus arizonica Green.; kult; srednja Amerika

P *Juniperus horizontalis Moench; kult; Sjeverna Amerika •

P Thuja occidentalis L.; kult; Sjeverna Amerika •

\section{Pinaceae}

$\mathrm{P}$ Cedrus atlantica (Endl.) Carrière; kult; sjeverna Afrika

P C. deodara (D. Don) G. Don fil.; kult; Himalaja •

\section{CYCADOPSIDA}

\section{Cycadaceae}

$\mathrm{P} *$ *ycas revoluta Thunb.; kult; istočna Azija

SPERMATOPHYTA

\section{DICOTYLEDONES}

\section{ANGIOSPERMAE}

\section{Actinidiaceae}

P Actinidia chinensis Planch.; kult; Kina

\section{Aizoaceae}

Ch *Aptenia cordifolia (L. fil.) N. E. Br.; inv; južna Afrika •

Ch Carpobrotus acinaciformis (L.) L. Bolus; inv; južna Afrika •

Ch *Delosperma cooperi (Hook.) L. Bolus; kult; južna Afrika •

Ch Mesembryanthemum crystallinum L.; kult; jugozapadna Afrika •

\section{Amaranthaceae}

$\mathrm{T}$ Amaranthus caudatus L.; cas; Južna Amerika

$\mathrm{T}$ A. cruentus L.; cas; srednja Amerika •

T A. deflexus L.; nat; Južna Amerika

$\mathrm{T}$ A. retroflexus L. (Pandža, 1998.); inv; Sjeverna Amerika

T Celosia argentea L. (incl. C. cristata L.); cas; tropska Azija •

$\mathrm{T}$ Gomphrena globosa L.; cas; tropi 
Marija Pandža: Alohtona flora naselja Jezera na otoku Murteru (Dalmacija, Hrvatska)

Anacardiaceae

P Rhus typhina L.; cas; Sjeverna Amerika

\title{
Apiaceae
}

$\mathrm{H}$ Apium graveolens L.; cas; Europa

H Petroselinum crispum (Mill.) A. W. Hill; cas; podrijetlo nepoznato

\section{Apocynaceae \\ Ch $*$ Catharanthus roseus (L.) G. Don; cas; Madagaskar • (sl. 2)}

\author{
Araliaceae \\ P *Hedera algeriensis Hibberd; kult; sjeverna Afrika (Alžir) • \\ $\mathrm{P} * H$. canariensis Willd.; kult; Kanarski otoci
}

\section{Asclepiadaceae}

P Araujia sericifera Brot.; cas.; Južna Amerika • (sl. 3)

\section{Asteraceae}

H *Ajania pacifica (Nakai) K. Bremer et Humphries; kult; istočna Azija (Japan) •

$\mathrm{T}$ Ambrosia artemisiifolia L. (Pandža i dr., 2001.); inv; Sjeverna Amerika

$\mathrm{H}$ *Argyranthemum frutescens (L.) Scultz.-Bip.; kult; Kanarski otoci •

$\mathrm{H}$ Artemisia verlotiorum Lamotte (Pandža i dr., 2001.); inv; istočna Azija

T Aster squamatus (Spreng.) Hieron. (Pandža i dr., 2001.); inv; srednja i Južna Amerika

T Bidens subalternans DC. (Pandža, 1998.); inv; Južna Amerika

$\mathrm{T}$ Calendula officinalis L.; cas; podrijetlo nepoznato

T Callistephus sinensis (L.) Ness; kult; Mongolija, Kina i istočna Azija •

$\mathrm{T}$ Chamomilla recutita (L.) Rauschert; nat; zapadna Azija

T Conyza bonariensis (L.) Cronquist (Pandža, 1998.); inv; srednja Amerika

T C. canadensis (L.) Cronquist (Pandža, 1998.); inv; Sjeverna Amerika

T C. sumatrensis (Retz.) E. Walker (Milović, 2004.); inv; tropska Amerika

$\mathrm{T}$ Cosmos bipinnatus Cav.; cas; Sjeverna Amerika

H Cynara scolymus L.; kult; Mediteran

G Dahlia variabilis (Willd.) Desf.; kult; Sjeverna Amerika

$\mathrm{T}$ Gaillardia pulchella Foug.; kult; Sjeverna Amerika •

Ch ${ }^{*}$ Gazania rigens (L.) Gaertn.; cas; južna Afrika •

$\mathrm{T}$ Helianthus annuus L.; kult; Sjeverna Amerika

G H. tuberosus L. (Pandža, 1998.); inv; Sjeverna Amerika

P *Leucophyta brownii Cass.; kult; Australija • 
$\mathrm{H}$ *Osteospermum jucundum (E. Phillips) Norl.; cas; južna Afrika •

Ch Santolina chamaecyparissus L.; kult; zapadni Mediteran

Ch *S. rosmarinifolia L. (= S. viridis Willd.); kult; Portugal, Španjolska, Francuska

Ch Senecio angulatus L. fil.; cas; južna Afrika

Ch S. bicolor (Willd.) Tod. ssp. cineraria (DC.) Chater; nat; zapadni Mediteran

H Solidago canadensis L.; cas; Sjeverna Amerika

$\mathrm{T}$ Tagetes erecta L.; kult; Meksiko i srednja Amerika •

T T. patula L.; cas; Meksiko i Gvatemala

H Tanacetum parthenium (L.) Sch.Bip.; cas; istočna Europa i zapadna Azija •

T Zinnia elegans Jacq.; kult; Meksiko

\section{Balsaminaceae}

T Impatiens balfourii Hooker fil.; cas; indijski podkontinent

$\mathrm{T} * I$. walleriana Hook.; kult; istočna Afrika •

T I. balsamina L.; kult; jugoistočnaAzija •

\section{Basellaceae}

P Anredera cordifolia (Ten.) Steenis; cas; Južna Amerika • (sl. 4)

\section{Begoniaceae}

G *Begonia cucullata Willdenow; kult; Južna Amerika •

\section{Berberidaceae}

P Mahonia aquifolium (Pursh.) Nutt.; kult; Sjeverna Amerika

\section{Bignoniaceae}

P Campsis radicans (L.) Seen.; cas; Sjeverna Amerika (sl. 5)

P Catalpa bignonioides Walter; kult; Sjeverna Amerika

P * Pandorea jasminoides (Lindl.) K. Schum.; cas; Australija

\section{Boraginaceae}

Ch Heliotropium arborescens L.; kult; Južna Amerika (Peru) •

\section{Brassicaceae}

T Brassica oleracea L. ssp. acephala (DC.) O. Schwarz; kult; hibrid •

T B. oleracea L. ssp. botrytis (L.) O. Schwarz; kult; hibrid

T Diplotaxis erucoides (L.) DC. (Pavletić i Pandža, 1994.); nat; zapadni Mediteran 
T Eruca vesicaria (L.) Cav. ssp. sativa (Mill.) Thell.; cas; Mediteran

Ch Erysimum cheiri (L.) Crantz (= Cheiranthus cheiri L.); cas; Mediteran

Ch Iberis sempervirens L.; kult; Mediteran

$\mathrm{H}$ Raphanus sativus L.; cas; podrijetlo nepoznato

\section{Buxaceae}

P Buxus sempervirens L.; kult; južna Europa, sjeverna Afrika, Turska

\section{Cactaceae}

P Opuntia ficus-indica (L.) Miller; cas; neotropi

Ch $*$ O. inbricata (Haworth) DC. (= Cylindropuntia $i$. Haw.) DC.); kult; Sjeverna Amerika •

Ch O. vulgaris Miller; nat; tropska Amerika

\section{Caprifoliaceae}

P *Abelia $\times$ grandiflora (Andre) Rehder; kult; hibrid •

P Lonicera japonica Thunb.; kult; Kina i istočna Azija •

\section{Caryophyllaceae}

Ch Cerastium tomentosum L.; cas; Mediteran (Italija)

H Dianthus caryophyllus L.; kult; Mediteran

\section{Celastraceae}

$\mathrm{P}$ Euonymus japonica L.f.; kult; istočna Azija (Japan i Koreja)

\section{Chenopodiaceae}

P Atriplex halimus L.; kult; južna Europa i sjeverna Afrika

T Bassia scoparia (L.) J.A. Scott; cas; srednja Azija •

H Beta vulgaris L. ssp. vulgaris; cas; Mediteran

$\mathrm{T}$ Spinacia oleracea L.; kult; jugozapadna Azija

\section{Cichoriaceae}

$\mathrm{T}$ Cichorium endivia L.; cas; Indija

T Lactuca sativa L.; cas; Azija

\section{Convolvulaceae}

T Ipomea purpurea Roth; cas; Južna Amerika

\section{Crassulaceae}

Ch *Sedum palmeri S.Watson; kult; Meksiko • 
Marija Pandža: Alohtona flora naselja Jezera na otoku Murteru (Dalmacija, Hrvatska)

\section{Cucurbitaceae}

T Citrullus lanatus (Thunb.) Mansfeld; cas; tropska Afrika

T Cucumis sativus L.; kult; jugoistočna Azija (Indija)

T Cucurbita pepo L.; kult; Sjeverna Amerika (SAD)

$\mathrm{T}$ Lagenaria siceraria (Molina) Standley; kult; tropska Afrika

$\mathrm{T}$ Sechium edule Swartz; kult; tropi

\section{Ebenaceae}

P Diospyros kaki L.f.; kult; Kina

\section{Euphorbiaceae}

T Euphorbia maculata L. (Pandža i dr., 2001.) ; inv; Sjeverna Amerika

Ch E. marginata Pursh; cas; Sjeverna Amerika (SAD)

T E. prostrata Aiton (Milović i Randić, 2001.) ; inv; Sjeverna Amerika

$\mathrm{T}$ Ricinus communis L.; cas; paleotropi

\section{Fabaceae}

P Acacia dealbata Link; kult; Australija •

P Albizzia julibrissin Durazz.; cas; srednja Azija

P Cercis siliquastrum L; cas; južna Europa i zapadna Azija

T Cicer arietinum L.; kult; jugozapadna Azija

P Medicago arborea L.; kult; Mediteran •

T Phaseolus vulgaris L.; cas; srednja i Južna Amerika

T Pisum sativum L.; kult; podrijetlo nepoznato

P Poinciana gilliesii Hook.; cas; Južna Amerika

P Robinia pseudoacacia L. (Pandža, 1998.); inv; Sjeverna Amerika

P Sophora japonica L.; kult; istočna Azija (Kina i Koreja)

T Vicia faba L.; cas; podrijetlo nepoznato

P Wisteria sinensis (Sims) Sweet; cas; istočna Azija (Kina)

\section{Garryaceae}

P Aucuba japonica Thunb.; kult; istočna Azija (Kina) •

\section{Geraniaceae}

Ch Pelargonium peltatum (L.) L'Hér.; kult; južna Afrika •

Ch P. zonale (L.) Aiton; kult; južna Afrika

\section{Grossulariaceae}

P Ribes uva-crispa L.; kult; istočna Europa i zapadna Azija 


\section{Juglandaceae}

P Juglans regia L.; cas; jugoistočna Europa i tropska Azija

\section{Lamiaceae}

Ch Lavandula angustifolia Mill.; kult; Mediteran

Ch $*$ L. dentata L.; kult; Mediteran (Europa, Afrika) •

Ch *L. stoechas L.; kult; Mediteran (sjeverna Afrika i Madeira) •

$\mathrm{H}$ Mentha spicata L.; cas; Europa i jugozapadna Azija •

$\mathrm{H} *$ Nepeta $\times$ faassenii Stearn $(=$ N. mussinii Spreng. ex Henckel); kult; hibrid •

T Ocimum basilicum L.; kult; tropska Afrika

$\mathrm{T}$ *Perilla frutescens (L.) Britt.; cas; istočna Azija (Kina) • (sl. 6a, b)

G *Physostegia virginiana (L.) Benth.; cas; Sjeverna Amerika •

P *Salvia microphylla Kunth; cas; Sjeverna Amerika (Meksiko) •

$\mathrm{T}{ }^{*}$ S. splendens Roemer \& Schultes; kult; Južna Amerika (Brazil)

$\mathrm{P} *$ Westringia fruticosa (Willd.) Druce; kult; Australija

\section{Lythraceae}

P Lagerstroemia indica L.; kult; istočna Azija (Kina) •

\section{Magnoliaceae}

P Magnolia grandiflora L.; kult; Sjeverna Amerika

$\mathrm{P} *$ *. xsoulangiana Soulange-Bodin; kult; hibrid

\section{Malvaceae}

$\mathrm{H}$ Alcea rosea $\mathrm{L}$.; cas; podrijetlo nepoznato

$\mathrm{P} *$ Hibiscus rosa-sinensis L.; kult; tropska Azija (Kina) •

P H. syriacus L.; cas; Kina i istočna Azija

\section{Meliaceae}

P Melia azedarach L.; cas; istočna Azija

\section{Moraceae}

P Broussonetia papyrifera (L.) Vent. (Pandža, 1998.); inv; istočna Azija

P Morus alba L.; nat; istočna Azija

P M. nigra L.; kult; jugozapadna Azija

\section{Myrtaceae}

$\mathrm{P} *$ Callistemon citrinus (Curtis) Skeels; kult; Australija 


\section{Nyctaginaceae}

P Bougainvillea spectabilis Willd.; cas; Južna America (Brazil)

G Mirabilis jalapa L.; nat; tropska Amerika

\section{Oleaceae}

$\mathrm{P} *$ *Forsythia $\times$ intermedia Zabel; kult; hibrid •

$\mathrm{P}$ *Jasminum azoricum L.; kult; Madeira

P J. nudiflorum Lindley; kult; Kina

P Ligustrum lucidum Aiton f.; cas; istočna Azija •

P Syringa vulgaris L.; cas; jugoistočna Europa (Balkan)

\section{Onagraceae}

$\mathrm{H} *$ *Gaura lindheimeri Engelm. \& A.Gray; kult; Sjeverna Amerika •

$\mathrm{H}$ Oenothera biennis L.; cas; Sjeverna Amerika

\section{Oxalidaceae}

G Oxalis articulata Savigny; nat; Južna Amerika

\section{Papaveraceae}

$\mathrm{T}$ Eschscholzia californica Cham.; cas; Sjeverna Amerika

$\mathrm{T}$ Papaver somniferum L.; cas; zapadni Mediteran

\section{Passifloraceae}

P Passiflora caerulea L.; cas; Južna Amerika

\section{Phytolaccaceae}

G Phytolacca americana L. (Pandža, 1998.); inv; Sjeverna Amerika

\section{Pittosporaceae}

P Pittosporum tobira (Thunb.) Aiton f.; cas; istočna Azija

\section{Platanaceae}

P Platanus acerifolia (Aiton) Willd. (P. hybridus Brot.); kult; hibrid •

\section{Plumbaginaceae}

G Ceratostigma plumbaginoides Bunge; kult; Kina •

$\mathrm{H} *$ Limonium sinuatum (L.) Mill.; cas; Mediteran •

P *Plumbago auriculata Lam.; cas; južna Afrika • 
Marija Pandža: Alohtona flora naselja Jezera na otoku Murteru (Dalmacija, Hrvatska)

Polygalaceae

P *Polygala myrtifolia L.; kult; južna Afrika

\section{Portulacaceae}

$\mathrm{T}$ Portulaca grandiflora Hooker; cas; Južna Amerika

\section{Proteaceae}

P *Grevillea rosmarinifolia Cunn.; kult; Australija

\section{Punicaceae}

P Punica granatum L.; nat; jugoistočna Europa i zapadna Azija

\section{Rhamnaceae}

P Ziziphus jujuba Miller; cas; tropska Azija

\section{Rosaceae}

$\mathrm{P} *$ Cotoneaster horizontalis Decaisne; kult; Kina

$\mathrm{P} *$ C. lacteus Smith; kult; Kina •

P Cydonia oblogna Mill.; cas; zapadna Azija

P Eryobotrya japonica (Thunb.) Lindl.; kult; istočna Azija (Kina, Japan)

$\mathrm{H}$ Fragaria $\mathrm{x}$ ananassa Duchesne; kult; hibrid $\bullet$

P Kerriajaponica (L.) DC.; cas; Kina i istočna Azija

P Malus domestica Borkh.; kult; Europa i zapadna Azija

P *Photinia $\times$ fraseri Dress; kult; hibrid •

P Prunus armeniaca L.; kult; srednja Azija (Kina)

P P. cerasifera Ehrh.; nat; zapadna Azija

P P. cerasus L.; kult; jugozapadna Azija

P P. domestica L.; cas; Europa i zapadna Azija

P P. dulcis (Miller) D. A. Webb.; cas; jugozapadna Azija

P P. laurocerasus L.; kult; jugozapadna Azija

P P. persica (L.) Batsch; cas; istočna Azija

P $\quad$ Spiraea $\times$ vanhouttei (Briot) Zabel; kult; hibrid •

\section{Rutaceae}

P Citrus aurantium L.; kult; jugoistočna Azija

P C. deliciosa Ten.; kult; istočna Azija

P C. limon (L.) Burm. fil.; cas; jugoistočna Azija

$\mathrm{P} *$ C. limetta Risso (Citrus $\times$ aurantifolia (Christm.) Swingle); kult; hibrid •

$\mathrm{P} *$ C. maxima Burm.; kult; hibrid • 
Marija Pandža: Alohtona flora naselja Jezera na otoku Murteru (Dalmacija, Hrvatska)

P C. sinensis (L.) Osbeck; kult; jugoistočna Azija (Kina) •

$\mathrm{P}{ }^{*}$ Fortunella margarita (Lour.) Swingle; kult; Kina

\section{Sapindaceae}

$\mathrm{T} *$ Cardiospermum halicacabum L.; cas; tropska Amerika •

\section{Saxifragaceae}

G Bergenia crassifolia (L.) Fritsch; kult; Azija •

P Hydrangea macrophylla (Thunb.) Ser.; kult; Kina i Japan

P Philadelphus coronarius L.; cas; južna Europa

\section{Scrophulariaceae}

Ch Antirrhinum majus L.; nat; jugozapadna Europa

$\mathrm{P} *$ Hebe speciosa (Cunningham) Cockayne \& Allan.; kult; Novi Zeland •

$\mathrm{T}$ Veronica persica Poir.; nat; zapadna Azija

\section{Simaroubaceae}

P Ailanthus altissima (Mill.) Swingle (Pandža, 1998.); inv; istočna Azija

\section{Solanaceae}

P *Brugmansia suaveolens (Humb. \& Bonpl. ex Willd.) Bercht. \& J. Presl; kult; Južna Amerika •

T Capsicum annuum L.; kult; Sjeverna, srednja i Južna Amerika

$\mathrm{T}$ C. frutescens L.; kult; Južna i srednja Amerika •

P *Cestrum elegans (Brongn.) Schtdl.; kult; Sjeverna Amerika (Meksiko) •

T Datura innoxia Mill. (Pandža, 1998.); inv; srednja Amerika

T D. stramonium L. (Pandža, 1998.); inv; tropska Amerika (SAD i Meksiko)

$\mathrm{P} *$ Lycianthes rantonneti (Carriere) Bitter; kult; Južna Amerika

T Petunia $\times$ hybrida Vilm.; kult; hibrid •

$\mathrm{T}$ Physalis peruviana L.; kult; Južna Amerika •

P *Solanum laxum Sprengel (= S. jasminoides Paxton); kult; Južna Amerika •

T S. lycopersicum L.; cas; srednja i Južna Amerika

$\mathrm{T}$ S. melongena L.; kult; indijski podkontinent

P *S. pseudocapsicum L.; cas; Južna Amerika

T S. tuberosum L.; cas; Južna Amerika

\section{Theaceae}

P Camellia japonica L.; kult; istočna Azija • 


\section{Tropaeolaceae}

$\mathrm{T}$ Tropaeolum majus L.; kult; hibrid

\section{Verbenaceae}

P *Aloysia citrodora Palau; kult; Južna Amerika •

P *Lantana camara L.; kult; tropska Amerika

$\mathrm{P} *$ *L. montevidensis (Sprengel) Briquet; kult; Južna Amerika •

\section{Violaceae}

$\mathrm{T} *$ *Viola $\times$ wittrockiana Gams; kult; hibrid

\section{Vitaceae}

P Parthenocissus quinquefolia (L.) Planchon; inv; Sjeverna Amerika

P P. tricuspidata (Sieb. et Zucc.) Planchon; kult; istočna Azija

$\mathrm{P}$ Vitis vinifera $\mathrm{L}$.; cas; podrijetlo nepoznato

\section{MONOCOTYLEDONES}

\section{Agavaceae}

P Agave americana L.; nat; Sjeverna Amerika

P Yucca aloifolia L.; kult; Sjeverna i srednja Amerika •

P Y. filamentosa L.; kult; Sjeverna Amerika •

P Y. gloriosa L.; cas; Sjeverna Amerika

\section{Amaryllidaceae}

G Narcissus pseudonarcissus L.; kult; Europa

G Sternbergia lutea (L.) Ker Gawl. ex Spreng.; cas; Mediteran

\section{Araceae}

G Zantedeschia aethiopica (L.) Sprengel; cas; južna Afrika

\section{Arecaceae}

P Chamaerops humilis L.; kult; Mediteran i sjeverna Afrika

$\mathrm{P}$ Phoenix canariensis Chabaud; cas; Kanarski otoci

P *Trachycarpus fortunei (Hooker) Wendl.; cas; Kina i istočna Azija •

P Washingtonia filifera (Linden) H. Wendl.; kult; Sjeverna Amerika

\section{Cannaceae}

G Canna indica L.; cas; tropi 
Marija Pandža: Alohtona flora naselja Jezera na otoku Murteru (Dalmacija, Hrvatska)

\section{Commelinaceae}

G Commelina communis L.; cas; Azija •

G *Tradescantia pallida (Rose) Hunt 'Purpurea'; kult; Sjeverna Amerika (Meksiko)

$\mathrm{G} *$ *T. virginiana L.; cas; Sjeverna Amerika

\section{Cyperaceae}

Hy *Cyperus alternifolius L.; cas; Afrika (Madagaskar) •

\section{Iridaceae}

G *Gladiolus $\times$ gandavensis Van Houthe; kult; hibrid •

G Iris germanica L (incl. I. florentina L.).; nat; podrijetlo nepoznato

G *I. xiphium L.; cas; Portugal, Španjolska, jugozapadna Francuska i južna Italija

\section{Liliaceae}

G *Agapanthus africanus (L.) Hoffmanns.; kult; južna Afrika •

G Allium ascalonicum L.; kult; istočni Mediteran i Azija

G A. серa L.; kult; zapadna Azija

$\mathrm{G}$ A. sativum L.; kult; srednja Azija

G *Asparagus densiflorus (Kunth) Jessop; cas; južna Afrika •

G Aspidistra elatior Blume; kult; Azija •

P Dasylirion serratifolium (Schult.) Zucc.; kult; Sjeverna Amerika (Meksiko) •

G *Hosta fortunei (Baker) Bailey; kult; sjeveroistočna Azija

G Hyacinthus orientalis L.; kult; srednja i južna Turska, sjeverozapadna Sirija i Libanon

G Lilium candidum L.; cas; zapadna i južna Grčka, jugozapadna Turska

G *Tulbaghia violacea Hard.; cas; južna Afrika •

$\mathrm{G} *$ Tulipa gesneriana L.; kult; tropska Azija •

\section{Poaceae}

H *Cortaderia selloana (Schult. \& Schult. f.) Asch. \& Graebn.; kult; Južna Amerika

P *Phyllostachys aurea Carriere \& Riviere; cas; Kina • 


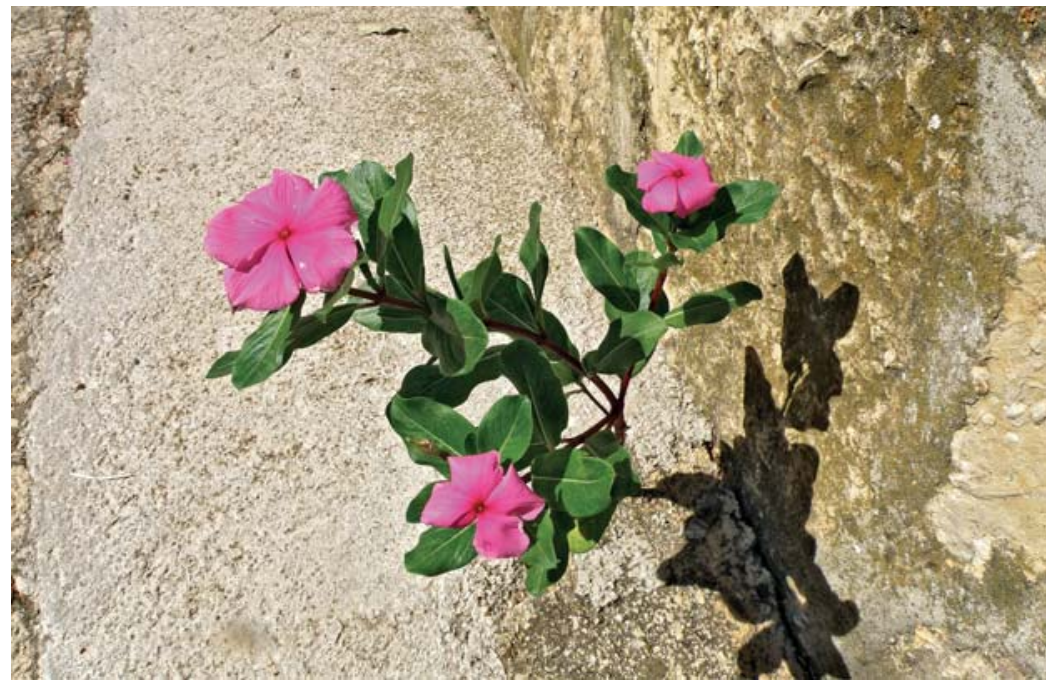

Slika 2. Vrsta Catharanthus roseus na ulici u Jezerima (Foto - 7. 9. 2013.) Figure 2 The species Catharanthus roseus on the street in the settlement of Jezera (photo taken on 7/9/2013.).

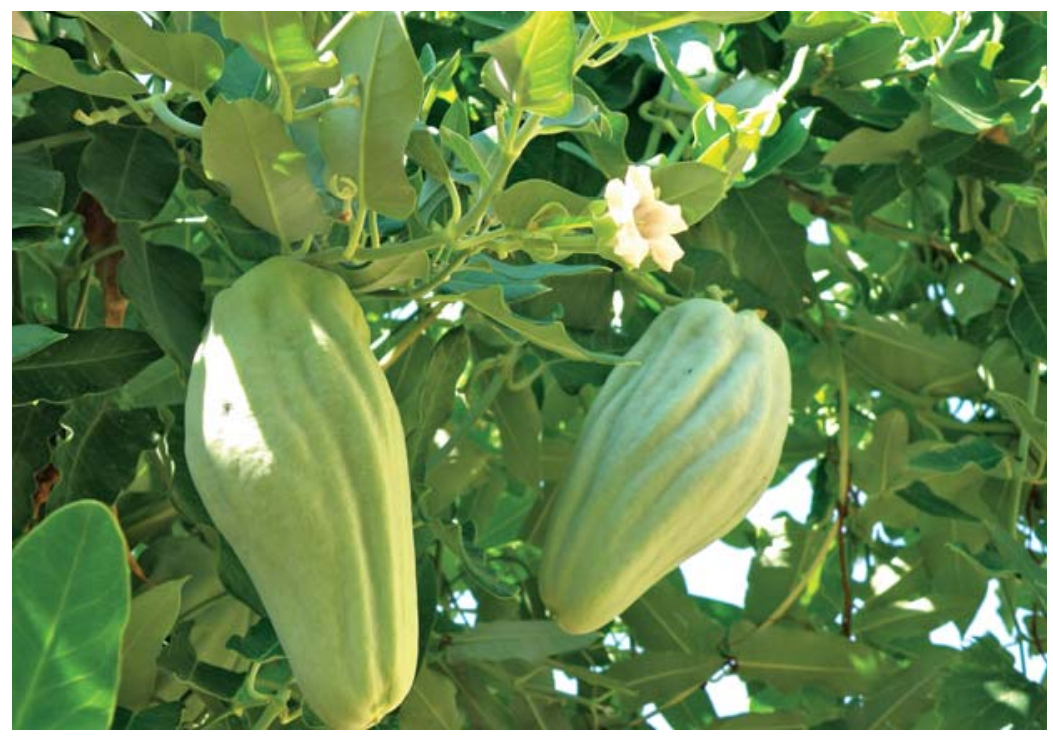

Slika 3. Araujia sericifera Brot.

Figure 3 Araujia sericifera Brot. 


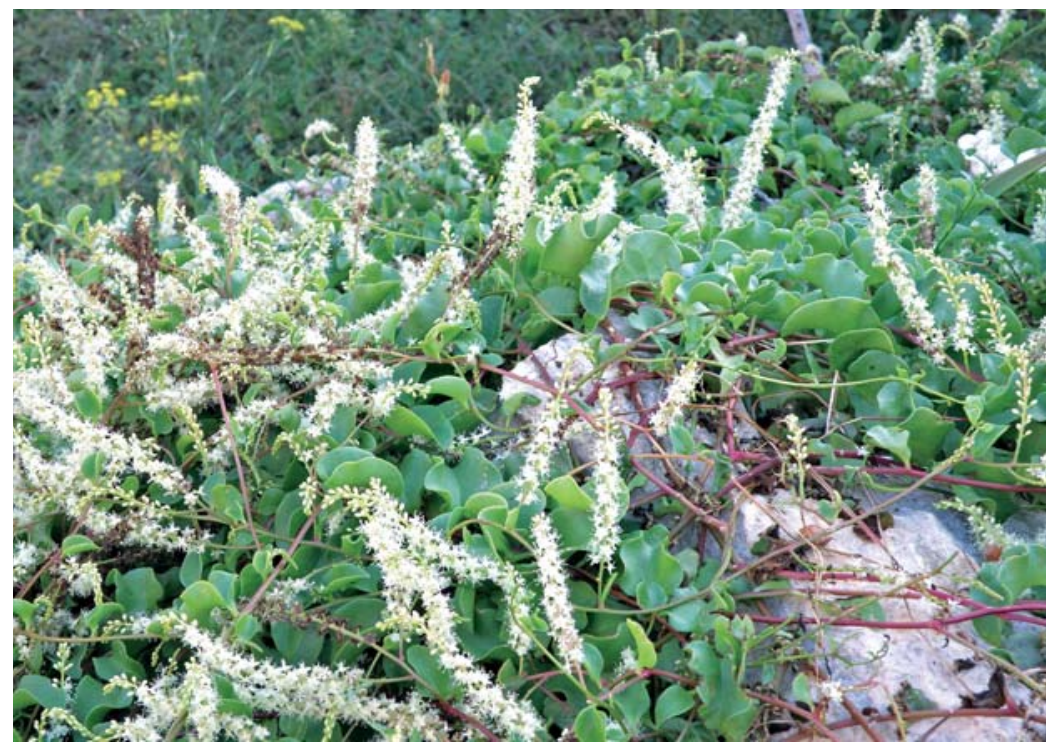

Slika 4. Anredera cordifolia (Ten.) Steenis

Figure 4 Anredera cordifolia (Ten.) Steenis

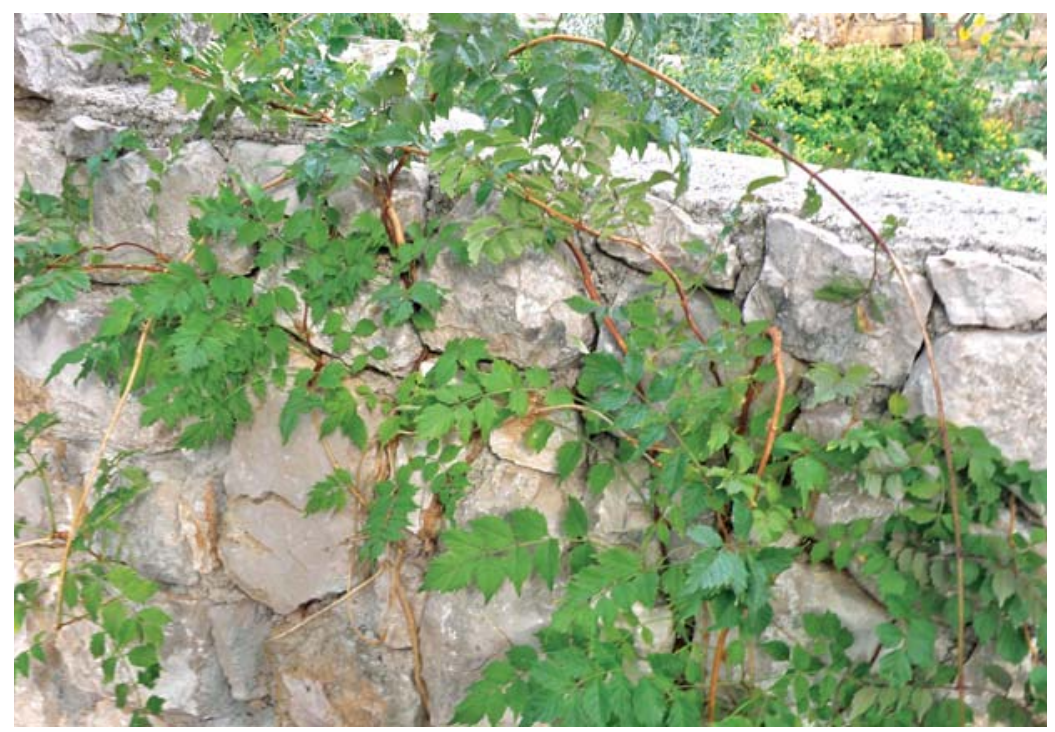

Slika 5. Campsis radicans (L.) Seen.

Figure 5 Campsis radicans (L.) Seen. 

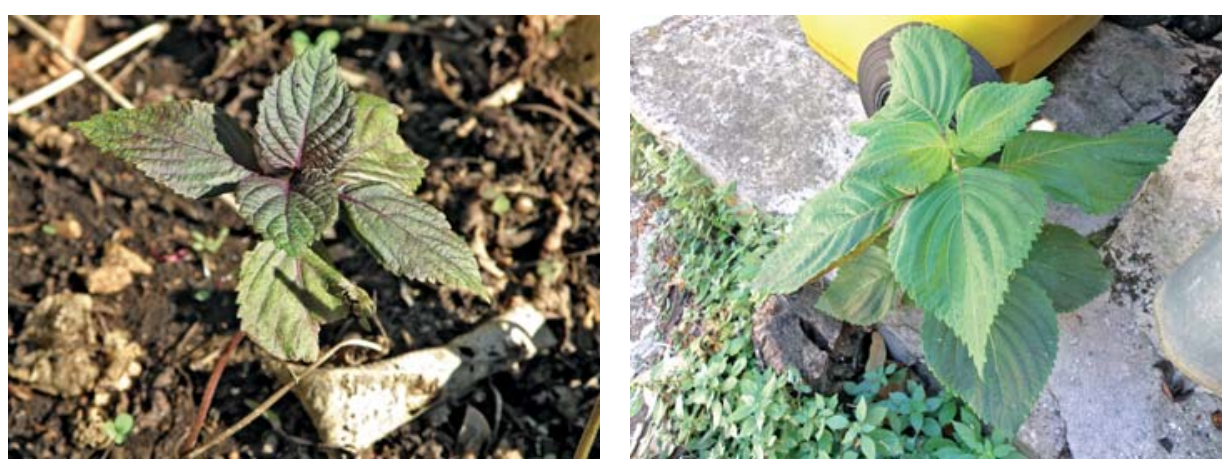

Slike 6a,b Perilla frutescens (L.) Britt.

Figures 6a,b Perilla frutescens (L.) Britt.

\section{ANALIZA ALOHTONE FLORE I RASPRAVA}

Analizom alohtone flore Jezera obuhvaćene su sve svojte koje dolaze isključivo u kulturi te svojte koje se samostalno razmnožavaju ili su nestalni prebjezi iz kulture.

U istraživanjima alohtone flore Jezera zabilježeno je 248 svojta od kojih je 95 vrsta i podvrsta novih za floru otoka Murtera. Ukupna flora otoka Murtera danas broji 977 svojta što je 19.5\% ukupne flore Hrvatske.

Navedene svojte (248) svrstane su u 196 rodova i 80 porodica što ukazuje na veliku raznolikost alohtone flore. Među alohtonim svojtama je 6 svojta golosjemenjača i 242 kritosjemenjače, s izrazitom dominacijom dvosupnica (209 svojti; 84,27\%) u odnosu na jednosupnice (33 svojte; 13,31\%) (tab. 1).

Tablica 1. Taksonomska analiza alohtone flore Jezera.

Table 1 Taxonomic analysis of the alien fora of the settlement of Jezera.

\begin{tabular}{|l|c|c|c|c|}
\hline \multirow{2}{*}{ Svojta (Taxa) } & \multirow{2}{*}{ Gymnospermae } & \multicolumn{2}{|c|}{ Angyospermae } & \multirow{2}{*}{$\begin{array}{c}\text { Ukupno } \\
\text { Total }\end{array}$} \\
\cline { 3 - 4 } & & Dicotyledones & Monocotyledones & 80 \\
\hline Porodice - Families & 3 & 67 & 10 & 196 \\
\hline Rodovi - Genera & 5 & 164 & 27 & 243 \\
\hline Vrste - Species & 6 & 204 & 33 & 5 \\
\hline Podvrste - Subspecies & & 5 & & 100,00 \\
\hline \multicolumn{1}{c|}{$\%$} & 2,42 & 84,27 & 13,31 & \\
\hline
\end{tabular}


Marija Pandža: Alohtona flora naselja Jezera na otoku Murteru (Dalmacija, Hrvatska)

Analizirana je raspodjela alohtone flore po porodicama (tab. 2).

Tablica 2. Porodice alohtone flore s 10 i više svojti u Jezerima.

Table 2 Families of alien flora of Jezera comprising 10 and more taxa.

\begin{tabular}{|l|c|c|}
\hline $\begin{array}{c}\text { Porodice } \\
\text { Families }\end{array}$ & $\begin{array}{c}\text { Broj vrsta i podvrsta } \\
\text { No. of species and subspecies }\end{array}$ & $\begin{array}{c}\text { \% od ukupne flore (248) } \\
\text { \% of total flora (248) }\end{array}$ \\
\hline Asteraceae s.s. & 30 & 12,10 \\
\hline Rosaceae & 16 & 6,45 \\
\hline Solanaceae & 14 & 5,65 \\
\hline Fabaceae & 12 & 4,84 \\
\hline Liliaceae & 12 & 4,84 \\
\hline Lamiaceae & 11 & 4,44 \\
\hline
\end{tabular}

Među porodicama, s najvećim brojem svojti ističu se Asteraceae s.s. (30 svojti; $12,10 \%$ ) zatim slijede sa znatno manjim udjelima Rosaceae (16 svojti; $6,45 \%)$ i Solanaceae sa 14 svojti (5,65\%) te Fabaceae i Liliaceae s $4,84 \%$, obje. Ovih pet porodica zajedno grade 33,88\% ukupne alohtone flore istraživanog područja (tab. 2). Navedene porodice su najzastupljenije i u alohtonoj flori Zadra (Milović, 2008.), Rima (Celesti Grapow, 1993.-1994.) i Patrasa u Grčkoj (Chronopoulos i Christodoulakis, 2000.).

Među rodovima ističe se rod Prunus (7 svojti) koji obuhvaća različito voće po vrtovima i uz okućnice (Prunus armeniaca, $P$. cerasus, $P$. domestica, $P$. dulcis, $P$. persica...). Zbog povoljnih klimatskih prilika neke vrste toga roda se samostalno razmnožavaju ( $P$. cerasifera), a druge su nestalni prebjezi iz kulture (P. dulcis, P. domestica, P. persica).

Po broju svojti iza roda Prunus je rod Citrus (6 svojti), a zatim slijede rodovi Solanum s pet svojti i Amaranthus s četiri svojte. Rodovi s po tri svojte su: Conyza, Impatiens, Opuntia, Euphorbia, Lavandula, Yucca i Allium dok su svi ostali rodovi zastupljeni s po dvije ili samo s jednom svojtom.

Spektar životnih oblika alohtone flore Jezera (s1. 7) pokazuje dominaciju fanerofita sa 109 svojti (43,95\%). Iza fanerofita po brojnosti slijede terofiti (64 svojte; 25,81\%) jednogodišnje vrste kratkog životnog ciklusa prilagođene na mediteransku klimu. 
Dominacija fanerofita rezultat je unošenja drvenastih vrsta u hortikulturu. U turističkom naselju Lovišća brojne su samonikle autohtone, ali i sađene alohtone drvenaste vrste. U prošlom stoljeću pomorci Jezera $\mathrm{su}$ s prekooceanskih plovidbi donosili drvenaste ukrasne vrste (grmove, penjačice, drveće). Mnoge od njih prebijegi su iz uzgoja te se uspijevaju održati subspontano ili kao udomaćene svojte na okolnim staništima (Albizzia julibrissin, Anredera cordifolia, Araujia sericifera, Campsis radicans, Melia azedarach, Passiflora caerulea, Poinciana gilliesii, Pittosporum tobira, Rhus typhina, Trachycarpus fortunei...). U neofitskoj flori Zadra je 21,23\% fanerofita (Milović, 2008.), a u alohtonoj flori Omiša 32,14\% (Tafra i dr., 2013.).

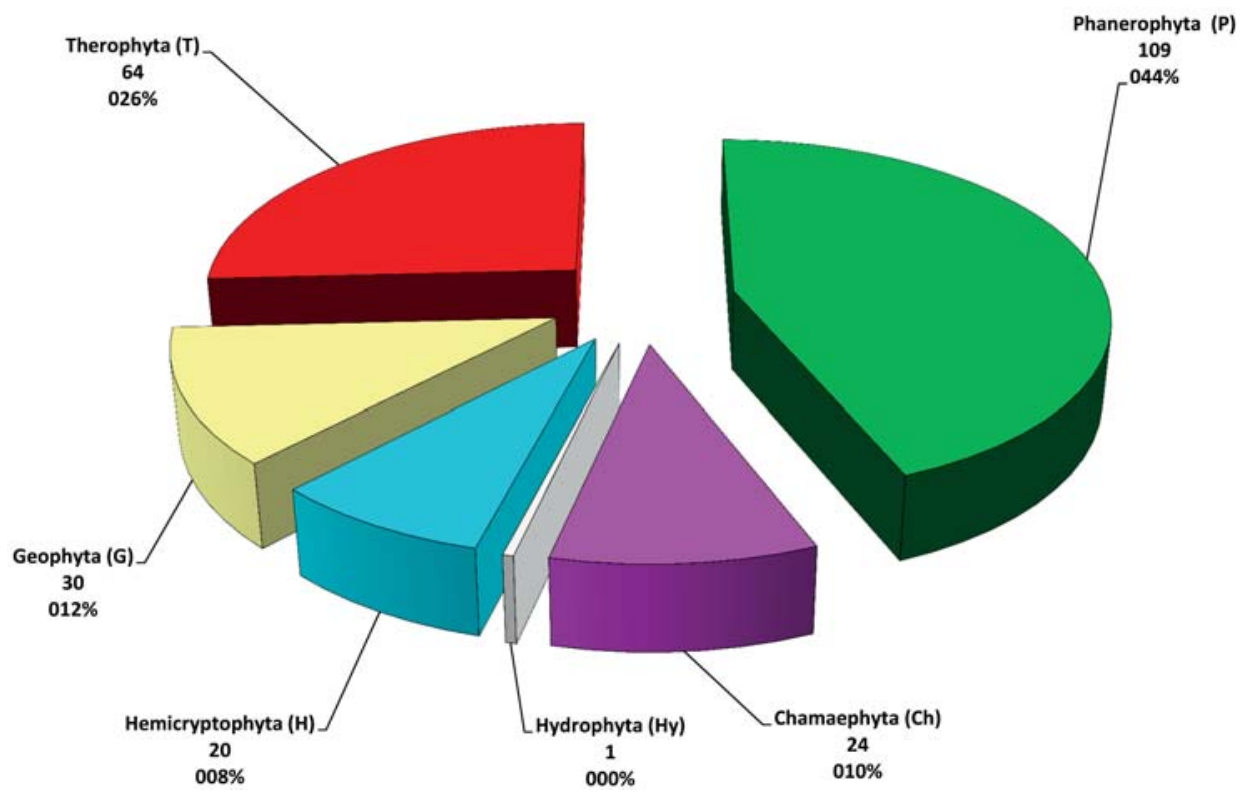

Slika. 7. Životni oblici u alohtonoj flori Jezera.

Figure 7 Life-forms of the alien flora of Jezera.

Broj vrsta i podvrsta alohtone flore Jezera prema stupnju naturalizacije prikazan je u tablici 3, a svojte koje preživljavaju izvan uzgoja predočene su na slici 8. 
Marija Pandža: Alohtona flora naselja Jezera na otoku Murteru (Dalmacija, Hrvatska)

Tablica 3. Alohtona flora Jezera prema stupnju naturalizacije.

Table 3 Alien flora of Jezera according to the degree of naturalization.

\begin{tabular}{|l|c|c|}
\hline $\begin{array}{c}\text { Stupanj naturalizacije } \\
\text { Degree of naturalization }\end{array}$ & $\begin{array}{c}\text { Broj vrsta i podvrsta } \\
\text { No. of species and subspecies }\end{array}$ & $\begin{array}{c}\text { \% od ukupne flore (248) } \\
\text { \% of total flora (248) }\end{array}$ \\
\hline U kulturi - In culture & 128 & 51,61 \\
\hline Povremene - Casual & 86 & 34,68 \\
\hline Invazivne - Invasive & 20 & 8,06 \\
\hline Naturalizirane - Naturalized & 14 & 5,65 \\
\hline Ukupno - Total & 248 & 100,00 \\
\hline
\end{tabular}

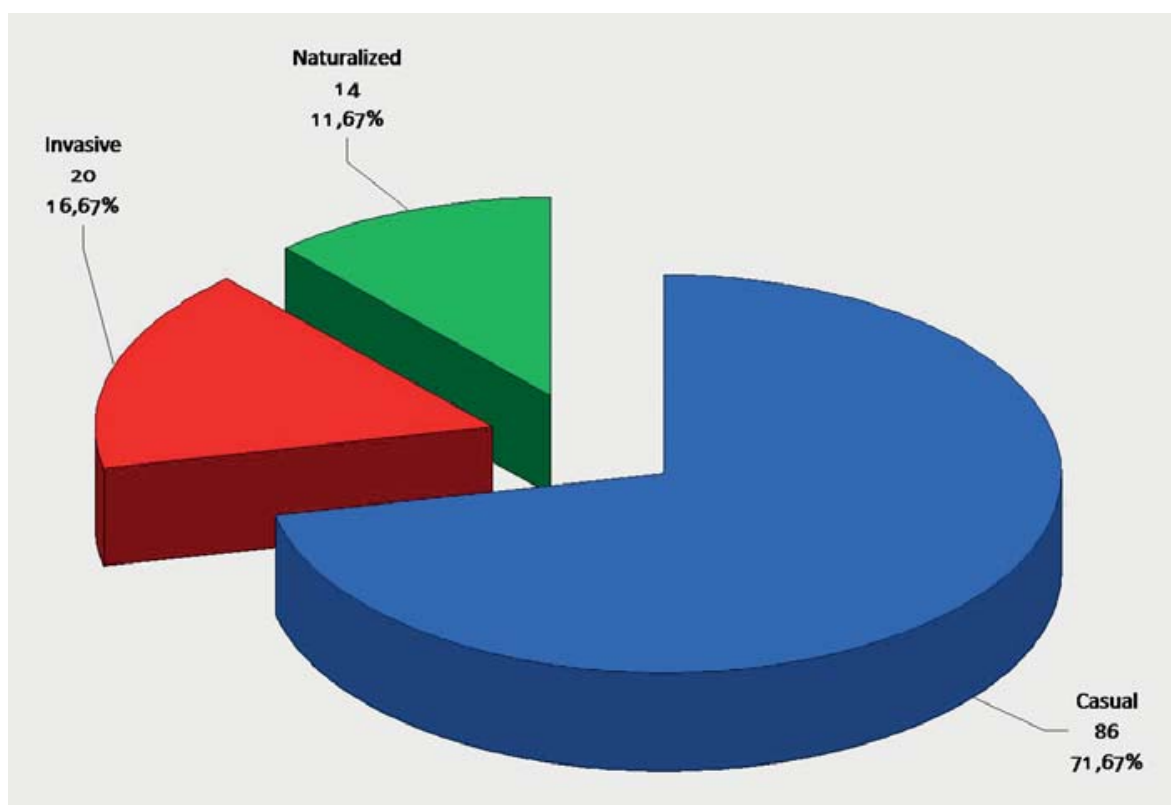

Slika 8. Svojte koje preživljavaju izvan uzgoja u alohtonoj flori Jezera.

Figure 8 Taxa of the alien flora of Jezera that survive outside cultivation.

Od 248 alohtonih svojti 128 svojta $(51,61 \%)$ je isključivo u kulturi i ne pokazuju tendenciju razmnožavanja izvan uzgoja, a 120 svojti (48,39\%) pokazuje sposobnost povremenog ili trajnog preživljavanja izvan uzgoja. Od 120 svojti najveća je zastupljenost neudomaćenih svojti (casual), 86 svojti $(71,67 \%)$, zatim slijede udomaćene invazivne $(16,67 \%)$, a najmanje su 
Marija Pandža: Alohtona flora naselja Jezera na otoku Murteru (Dalmacija, Hrvatska)

zastupljene udomaćene-neinvazivne $(11,66 \%)$. Slične rezultate, s dominacijom neudomaćenih svojti u urbanoj flori Zadra, navodi Milović (2008.): 72,28\% neudomaćenih, slijede udomaćene neinvazivne $(16,19 \%)$ i udomaćeneinvazivne $(11,43 \%)$.

U alohtonoj flori Jezera vrste koje pokazuju tendenciju invazivnog širenja (18) su: Ailanthus altissima, Amaranthus retroflexus, Ambrosia artemisiifolia, Artemisia verlotiorum, Aster squamatus, Bidens subalternans, Broussonetia papyrifera, Conyza bonariensis, C. canadensis, C. sumatrensis, Datura innoxia, D. stramonium, Helianthus tuberosus, Euphorbia maculata, E. prostrata, Parthenocissus quinquefolia, Phytolacca americana i Robinia pseudoacacia. Te vrste se nalaze i na preliminarnom popisu invazivnih vrsta Hrvatske. Većina invazivnih svojti: Bidens subalternans, Conyza bonariensis, C. canadensis, C. sumatrensis, Euphorbia prostrata... širi se na antropogena staništa. Vrste s preliminarnog popisa (Amaranthus deflexus, Diplotaxis erucoides i Veronica persica) su u flori Jezera udomaćene-neinvazivne dok su Solidago canadensis, Impatiens balfourii, Opuntia ficus-indica i Oenothera biennis povremeni prebjezi iz kulture (casual). Solidago canadensis (Marković, 1970.) i Impatiens balfourii (Ilijanić i dr., 1994.) se invazivno šire u unutrašnjosti Hrvatske dok su u priobalju i na otocima, uglavnom, nestalni prebjezi iz kulture. Vrsta Mesembryanthemum crystallinum u flori Jezera je u kulturi dok su vrste Aptenia cordifolia i Carpobrotus acinaciformis u flori Jezera potencijalno invazivne. Obje vrste potječu s juga Afrike iz klimatskog područja sličnog klimi u Jezerima.

Među neudomaćenim alohtonim svojtama su vrste dugo prisutne u kulturi (voće i povrće) koje se šire subspontano (Apium graveolens, Beta vulgaris ssp. vulgaris, Citrullus lanatus, Lactuca sativa, Petroselinum crispum, Prunus cerasifera, P. dulcis, P. persica, Raphanus sativus...).

Analiza alohtone flore Jezera prema geografskom podrijetlu svojti (tab. 4) pokazuje najveću zastupljenost biljaka američkog podrijetla (80 svojti; 32,26\%), među kojima je najviše onih koje potječu iz Sjeverne Amerike. Značajno su zastupljene i biljke azijskog podrijetla (69 svojti; 27,83\%).

U alohtonoj flori Zadra iz Amerike je 44,752\% svojti, a iz Azije 25,34\% (Milović, 2008.). U alohtonoj flori Omiša iz Amerike je 47,62\%, a zatim slijede svojte azijskog podrijetla, 29,76\% (Tafra i dr., 2013.). U flori Patrasa (Chronopoulos i Christodoulakis, 2000.) i Rima (Celesti Grapow, 1993.-1994.) iz Amerike je (47,3 \% i 32,8\%) i Azije (22,6 \% i 29,69\%). Prevladavajuća zastupljenost alohtonih svojti u flori Jezera kao i u florama drugih mediteranskih gradova (Omiša, Zadra, Rima...) je opravdana, uzimajući u obzir prometne veze Europe s Amerikom i Azijom. 
Marija Pandža: Alohtona flora naselja Jezera na otoku Murteru (Dalmacija, Hrvatska)

Tablica 4. Geografsko podrijetlo alohtone flore Jezera.

Table 4 Geographical origin of alien flora of Jezera.

\begin{tabular}{|c|c|c|c|c|c|}
\hline & \multicolumn{2}{|c|}{ Geografsko područje - Geographical origins } & \multicolumn{2}{|c|}{$\begin{array}{l}\text { Broj svojta } \\
\text { No. of taxa }\end{array}$} & $\%$ \\
\hline \multirow{7}{*}{1.} & \multirow{7}{*}{$\begin{array}{l}\text { AMERIKA } \\
\text { America }\end{array}$} & Sjeverna - North & 37 & \multirow{7}{*}{80} & \multirow{7}{*}{32,26} \\
\hline & & Srednja - Central & 4 & & \\
\hline & & \begin{tabular}{|l|} 
Sjeverna i srednja - \\
North and Central \\
\end{tabular} & 5 & & \\
\hline & & Srednja i Južna - Central and South & 4 & & \\
\hline & & Južna - South & 23 & & \\
\hline & & \begin{tabular}{|l|} 
Sjeverna, srednja i Južna - \\
North, Central and South \\
\end{tabular} & 1 & & \\
\hline & & Tropska - Tropical & 6 & & \\
\hline 2. & \multicolumn{3}{|c|}{ AUSTRALIJA I NOVI ZELAND - Australia and New Zealand } & 7 & 2,82 \\
\hline \multirow{7}{*}{3.} & \multirow{7}{*}{ AZIJA - Asia } & $\begin{array}{l}\text { Zapadna i jugozapadna Azija } \\
\text { West and South-West Asia }\end{array}$ & 13 & \multirow{7}{*}{69} & \multirow{7}{*}{27,83} \\
\hline & & \begin{tabular}{|l|} 
Sjeveroistočna i jugoistočna Azija \\
North-East and South- East Asia \\
\end{tabular} & 6 & & \\
\hline & & Istočna Azija - East Asia & 20 & & \\
\hline & & Srednja Azija - Central Asia & 9 & & \\
\hline & & Tropska Azija - Tropical Asia & 4 & & \\
\hline & & $\begin{array}{l}\text { Kina i istočna Azija } \\
\text { China and East Asia }\end{array}$ & 14 & & \\
\hline & & \begin{tabular}{|l|} 
Indijski podkontinent \\
Indian Subcontinent
\end{tabular} & 3 & & \\
\hline \multirow{5}{*}{4.} & \multirow{5}{*}{ AFRIKA - Africa } & Sjeverna Afrika - North Africa & 2 & & \\
\hline & & Južna Afrika - South Africa & 14 & & \\
\hline & & \begin{tabular}{|l} 
Jugozapadna Afrika - \\
South-West Africa \\
\end{tabular} & 1 & 23 & 9,27 \\
\hline & & Istočna Afrika - East Africa & 3 & & \\
\hline & & Tropska Afrika - Tropical Africa & 3 & & \\
\hline \multirow{5}{*}{5.} & \multirow{5}{*}{ EUROPA - Europe } & $\begin{array}{l}\text { Jugozapadna Europa } \\
\text { South-West Europe }\end{array}$ & 1 & \multirow{5}{*}{27} & \multirow{5}{*}{10,89} \\
\hline & & Europa - Europe & 2 & & \\
\hline & & Kanari - Canary Islands & 4 & & \\
\hline & & Južna Europa - South Europe & 4 & & \\
\hline & & Mediteran - Mediterannean & 16 & & \\
\hline
\end{tabular}


Marija Pandža: Alohtona flora naselja Jezera na otoku Murteru (Dalmacija, Hrvatska)

\begin{tabular}{|c|c|c|c|c|c|}
\hline \multirow{7}{*}{6.} & \multirow{7}{*}{$\begin{array}{l}\text { EUROPA, } \\
\text { AFRIKA } \\
\text { I AZIJA } \\
\text { Europe, } \\
\text { Africa } \\
\text { and Asia }\end{array}$} & $\begin{array}{l}\text { Južna Europa i sjeverna Afrika } \\
\text { South Europe and North Africa }\end{array}$ & 2 & \multirow{7}{*}{13} & \multirow{7}{*}{5,24} \\
\hline & & $\begin{array}{l}\text { Mediteran i sjeverna Afrika } \\
\text { Mediterranean and Norh Africa }\end{array}$ & 1 & & \\
\hline & & $\begin{array}{l}\text { Istočna i jugoistočna Europa i } \\
\text { zapadna Azija - East and South- } \\
\text { East Europe and West Asia }\end{array}$ & 3 & & \\
\hline & & $\begin{array}{l}\text { Istočni Mediteran i Azija } \\
\text { East Mediterranean and Asia }\end{array}$ & 1 & & \\
\hline & & $\begin{array}{l}\text { Južna Europa i zapadna Azija } \\
\text { South Europe and West Asia }\end{array}$ & 1 & & \\
\hline & & $\begin{array}{l}\text { Jugoistočna Europa i tropska Azija } \\
\text { South-East Europe and Tropical Asia }\end{array}$ & 2 & & \\
\hline & & $\begin{array}{l}\text { Europa te zapadna i jugozapadna Azija } \\
\text { Europe, West and South-West Asia }\end{array}$ & 3 & & \\
\hline 7. & \multicolumn{3}{|c|}{ U kulturi (hibrid) - In culture } & 16 & 6,45 \\
\hline 8. & \multicolumn{3}{|c|}{ Paleotropi - Paleotropics } & 1 & 0,40 \\
\hline 9. & \multicolumn{3}{|c|}{ Tropi i neotropi - Tropics and Neotropics } & 4 & 1,61 \\
\hline 10. & \multicolumn{3}{|c|}{ Podrijetlo nepoznato - Unknown origin } & 8 & 3,23 \\
\hline \multicolumn{4}{|c|}{ Ukupno - Total } & 248 & 100,00 \\
\hline
\end{tabular}

\section{ZAKLJUČCI}

Alohtona flora naselja Jezera na otoku Murteru broji 248 svojti od kojih je 95 novih za floru otoka Murtera. Ukupna flora otoka sada broji 977 vrsta i podvrsta što je 19,5\% ukupne flore Hrvatske. Porodica s najvećim brojem vrsta je Asteraceae s.s. (30 svojti), a od rodova ističe se rod Prunus (7 svojti).

U spektru životnih oblika dominiraju fanerofiti (109 svojti; 43,95\%) što je rezultat unošenja grmova i drveća u hortikulturu, a iza njih slijede terofiti (64 svojte; 25,81\%) jednogodišnje vrste prilagođene mediteranskoj klimi.

Od 248 alohtonih svojti $128(51,61 \%)$ je isključivo u kulturi, a 120 pokazuje sposobnost preživljavanja izvan uzgoja: 86 svojti su povremeni prebjezi, 20 je invazivnih i 14 udomaćenih. Najveću opasnost po prirodnu i poluprirodnu vegetaciju pokazuje vrsta Aster squamatus koja se uselila na vlažno stanište „Lokvu“ gdje se ekspanzivno širi. To vrijedno stanište je nepovratno uništeno ako se u skoroj budućnosti ne poduzmu odgovarajuće mjere.

Prema geografskom podrijetlu najveći broj svojti potječe iz Amerike (80 svojti; 32,26\%), a zatim slijede svojte iz Azije. 
Marija Pandža: Alohtona flora naselja Jezera na otoku Murteru (Dalmacija, Hrvatska)

Strane vrste su potencijalno opasne za autohtonu floru i stanovništvo jer su prenosnici bolesti i štetnika, alergena, a mnoge od njih se udomaćuju i invazivno šire. $U$ hortikulturi strane vrste treba zamijeniti autohtonima koje su lakše za održavanje i bolje prilagođene stanišnim prilikama.

\section{ZAHVALA}

Zahvaljujem turističkoj zajednici Jezera na financijskoj potpori u izradi rada i njezinom direktoru Nenadu Milinu.

\section{LITERATURA}

1. Boršić, I., Milović, M., Dujmović, I., Bogdanović, S., Cigić, P., Rešetnik, I., Nikolić, T., Mitić, B. (2008.): Preliminary check-list of invazive alien plant species (IAS) in Croatia. Nat. Croat. 17(2): 55-71.

2. Celesti Grapow, L. (1993.-1994.): La classificazione della flora Esotica di Roma. Studio preliminare. Allionia 32: 119-123.

3. Chronopoulos, G., Christodoulakis, D. (2000.): Analysis of the adventive flora of a Greek city: The example of Patras. Botanica Helvetica 110: 171-189.

4. Domac, R. (1994.): Flora Hrvatske. Priručnik za određivanje bilja. Šk. knj. Zagreb, pp. 504.

5. Duplančić Leder, T., Ujević, T., Čala, M. (2004.): Coastline Lengths and Areas of Islands in the Croatian Part of the Adriatic Sea Determined from the Topographic Maps at the Scale of $1: 25$ 000, Geoadria 9 (1): 5-32.

6. Cullen, J., Alexander, J. C. M., Brady, A., Brickell, C. D., Green, P. S., Heywood, V. H., Jörgensen, P.-M., Jury, S. L., Knees, S. G., Leslie, A. C., Matthews, V. A., Robson, N. K. B., Walters, S. M., Wijnands, D. O., Yeo, P.F., (eds.) (1995.-1999.): The Europaean Garden Flora Vol. 4-6, Cambridge University Press, Cambridge.

7. Horvat, I. (1949.): Nauka o biljnim zajednicama. Nakladni zavod Hrvatske, Zagreb.

8. Ilijanić, Lj., Marković, Lj., Stančić, Z. (1994): Impatiens balfourii Hooker fil. in Kroatien. Acta Bot. Croat. 53: 115-119. 
9. Marković, Lj. (1970): Prilozi neofitskoj flori savskih obala u Hrvatskoj. Acta Bot. Croat. 29: 203-2011.

10. Milović, M. (2004.): Naturalised species from the genus Conyza Less. (Asteraceae) in Croatia. Acta Bot. Croat. 63(2): 147-170.

11. Milović, M. (2008.): Urbana flora Zadra. Disertacija. Biološki odsjek, Prirodoslovno-matematički fakultet Sveučilišta u Zagrebu. Zagreb.

12. Milović, M., Pandža, M. (2010.): A contribution to the vascular flora of the Šibenik archipelago islands (Dalmatia, Croatia). Nat. Croat., 19(1): 179-203.

13. Milović, M., Randić, M. (2001.): New localities of Euphorbia prostrata Aiton (= Chamaesyce prostrata (Aiton) Small) in Croatia. Nat. Croat. 10(2): 89-95.

14. Mitić, B., Boršić, I., Dujmović, I., Bogdanović, S., Milović, M., Cigić, P., Rešetnik, I., Nikolić, T. (2008.): Alien flora of Croatia: proposals for standards in terminology, criteria and related database. Nat. Croat. 17(2): 73-90.

15. Nikolić, T. (ed.), (2017.): Flora Croatica Database. On-Line, URL: http://hirc.botanic.hr/fcd. Botanički zavod, Prirodoslovno-matematički fakultet Sveučilišta u Zagrebu. Zagreb.

16. Pandža, M. (1998.): Flora of the island of Murter (Central Adriatic). Acta Bot. Croat. 57, 99-122.

17. Pandža, M. (2002.): New localities of the species Convolvulus cneorum L. (Convolvulaceae) in Croatia. Nat. Croat. 11(1), 113-118.

18. Pandža, M. (2003.): Vegetacija otoka Murtera. Disertacija. Biološki odsjek, Prirodoslovno-matematički fakultet Sveučilišta u Zagrebu. Zagreb.

19. Pandža, M. (2004.): Vegetation of Phoenician juniper macchia Pistacio lentisci-Juniperetum phoeniceae Trinajstić 1987 (OleoCeratonion) on the island of Murter and small surrounding islands. Nat. Croat. 13(3), 201-212.

20. Pandža, M., Franjić, J., Trinajstić, I., Škvorc, Ž., Stančić, Z. (2001.): The most recent state of affairs in the distribution of some neophytes in Croatia. Nat. Croat. 10(4): 259-275. 
21. Pandža, M., Franjić, J., Škvorc., Ž. Trinajstić., I., Pavletić, Zi. (2004.): Šumska vegetacija otoka Murtera. Rad. Šumar. Inst. (Jastrebarsko) 39(2), 131-162.

22. Pandža, M., Franjić, J., Škvorc., Ž. (2005.): Weed and ruderal vegetation (Stellarietea mediae R. Tx. et al. ex von Rochow 1951) in the central part of the East Adriatic coast. Periodicum biologorum 107(3), 361-372.

23. Pavletić, Zi., Pandža, M. (1994.): Diplotaxis erucoides (L.) DC. (Brassicaceae) u Hrvatskoj flori. Fragm. phytom. herbol. 22(1-2), 25-28.

24. Pignatti, S. (1982.): Flora d'Italia. I-III. Edagricole. Bologna.

25. Pyšek, P., Richardson, D. M., Rejmanek, M., Webster, G. L., Williamson, M., Kirschner, J. (2004.): Alien plants in checklists and floras: towards better comunication between taxonomists and ecologists. Taxon 53(1): 131-143.

26. Richardson, D. M., Pyšek, P., Rejmanek, M., Barbour, M. G., Panetta, F. D., West, C. J. (2000.): Naturalization and invasion of alien plants: concepts and definitions. Diversity and Distributions 6: 93-107.

27. Šegota, T., Filipčić, A. (2003.): Köppenova klima i hrvatsko nazivlje. Geoadria 8(1): 17-37.

28. Tafra, D., Milović, M., Pandža, M. (2013): Non-native flora of the town of Omiš. (Dalmatia, Croatia). Nat. Croat. 22(1): 135-146.

29. Trinajstić, I. (1998.): Fitogeografsko rasčlanjenje klimazonalne šumske vegetacije Hrvatske. Šumarski list 122(9-10): 407-421.

30. Tutin T. G., Burges N. A., Chater A. O., Edmondson J. R., Heywood V. H., Moore D. M., Valentine D. H., Walters S. M., Webb D. A., eds., (1993.): Flora Europaea, Vol. 1, 2nd ed., Cambridge Univ. Press, Cambridge, 303-305.

31. Tutin, T. G., Heywood, V. H., Burges, N. A., Moore, D. M., Valentine, D. H., Walters, S. M., Webb, D. A., eds. (1968.-1980.): Flora Europaea 2-5. University press. Cambridge.

32. Visiani, R. (1842.-1852.): Flora Dalmatica I-III, Lipsiae. 
33. Walters, S. M., Brady, A., Brickell, C. D., Cullen, J., Green, P. S., Lewis, J., Matthews, V. A., Webb, D. A., Yeo, P. F., Alexander, J. C. M., Heywood, V.H., Robson, N. K. B., Jorgensen, P-M., Jury, S. L., Kneews, S. G., Leslie, A. C., Wijnands, D. O., (eds.) (1984.-1989): The Europaean Garden Flora, I-III. University Press. Cambridge.

Adresa autora - Author's adress:

Primljeno -received:

doc. dr. sc. Marija Pandža

15.06.2017.

marija.pandza@si.t-com.hr

OŠ Murterski škoji, Put škole 8

22243 Murter 